\title{
Smart Technologies Enable Homes to Be Efficient and Interactive with the Grid
}

Approved for public release. Distribution is unlimited.

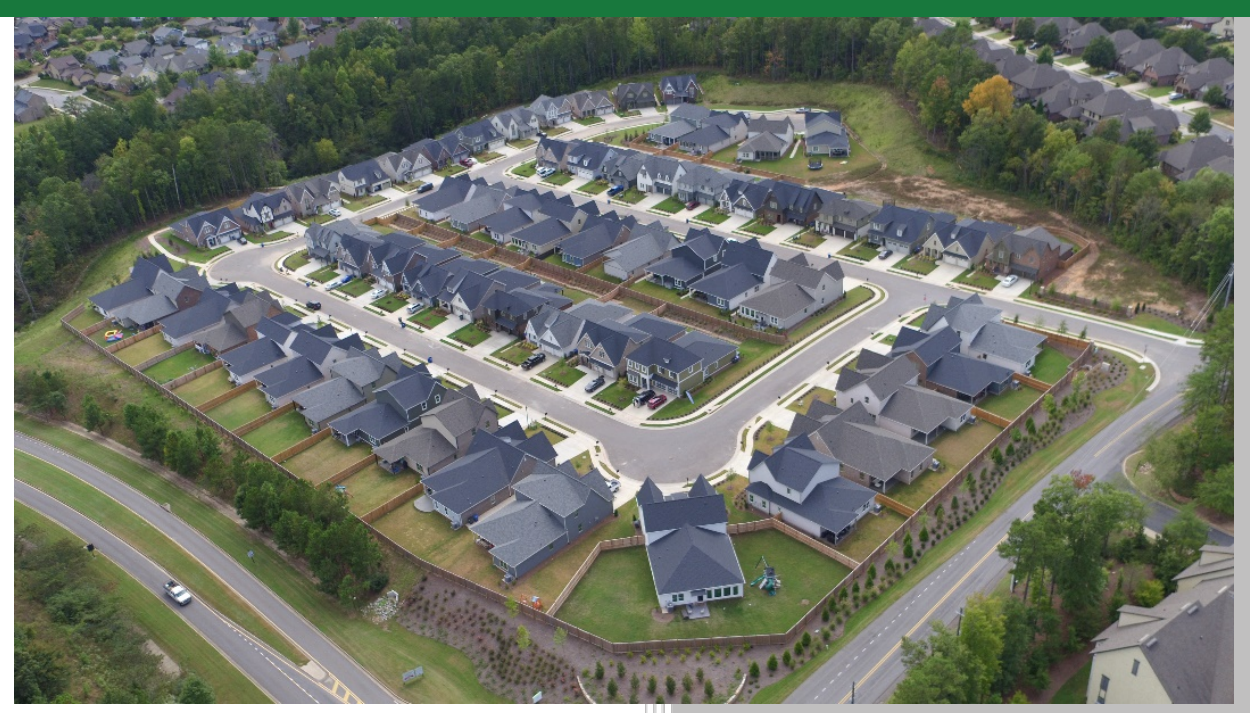

Heather Buckberry Jennifer Burke Michael Starke Helia Zandi Jeff Munk Supriya Chinthavali Chris Winstead Ben Ollis Joe Hagerman Teja Kuruganti Drew Herron Josh Hambrick Patrick Brukiewa Ron Ott Justin Hill Jim Leverette Phil Markham

Pradeep Vitta

April 2020 


\title{
DOCUMENT AVAILABILITY
}

Reports produced after January 1, 1996, are generally available free via US Department of Energy (DOE) SciTech Connect.

\section{Website www.osti.gov}

Reports produced before January 1, 1996, may be purchased by members of the public from the following source:

\author{
National Technical Information Service \\ 5285 Port Royal Road \\ Springfield, VA 22161 \\ Telephone 703-605-6000 (1-800-553-6847) \\ TDD 703-487-4639 \\ Fax 703-605-6900 \\ E-mail info@ntis.gov \\ Website http://classic.ntis.gov/
}

Reports are available to DOE employees, DOE contractors, Energy Technology Data Exchange representatives, and International Nuclear Information System representatives from the following source:

Office of Scientific and Technical Information

PO Box 62

Oak Ridge, TN 37831

Telephone 865-576-8401

Fax 865-576-5728

E-mail reports@osti.gov

Website http://www.osti.gov/contact.html

This report was prepared as an account of work sponsored by an agency of the United States Government. Neither the United States Government nor any agency thereof, nor any of their employees, makes any warranty, express or implied, or assumes any legal liability or responsibility for the accuracy, completeness, or usefulness of any information, apparatus, product, or process disclosed, or represents that its use would not infringe privately owned rights. Reference herein to any specific commercial product, process, or service by trade name, trademark, manufacturer, or otherwise, does not necessarily constitute or imply its endorsement, recommendation, or favoring by the United States Government or any agency thereof. The views and opinions of authors expressed herein do not necessarily state or reflect those of the United States Government or any agency thereof. 
Energy and Transportation Science Division

\title{
SMART TECHNOLOGIES ENABLE HOMES TO BE EFFICIENT AND INTERACTIVE WITH THE GRID
}

Oak Ridge National Laboratory: Heather Buckberry, Jennifer Burke, Michael Starke, Helia Zandi, Jeff Munk, Supriya Chinthavali, Chris Winstead, Ben Ollis, Joe Hagerman, Teja Kuruganti, Drew Herron, Josh Hambrick, Patrick Brukiewa, Ron Ott

Southern Company: Justin Hill, Jim Leverette, Phil Markham, Pradeep Vitta

Date Published: April 2020

\author{
Prepared by \\ OAK RIDGE NATIONAL LABORATORY \\ Oak Ridge, TN 37831-6283 \\ managed by \\ UT-BATTELLE, LLC \\ for the \\ US DEPARTMENT OF ENERGY
}

This material is based upon work supported by the U.S. Department of Energy

Office of Science, Office of Energy Efficiency and Renewable Energy, Building Technologies Office under contract DE-AC05-00OR22725

Cover Image: Reynolds Landing Alabama Power Smart Neighborhood ${ }^{\circledR}$

Photo provided by Southern Company 


\section{SMART TECHNOLOGIES ENABLE HOMES TO BE EFFICIENT AND INTERACTIVE WITH THE GRID}

Introducing control technologies like smart sensing and metering is transforming our buildings and power systems. These added technologies impact generation to consumption with unprecedented granularity in data, monitoring, intelligence and control. Electric distribution infrastructure is experiencing rapid changes with the adoption of solar photovoltaic (PV), electric vehicles and grid-edge customer devices.. Buildings, through responsive loads, will play a key role in finding solutions that both optimize the power system while enabling customer technologies and energy choices. Oak Ridge National Laboratory (ORNL) researchers, in collaboration with Southern Company and its subsidiaries Alabama Power and Georgia Power, are pioneering a future where smart homes and smart neighborhoods can benefit both homeowners and utilities by reducing energy consumption and peak demand.

\section{RESEARCH ENABLES A SMART FUTURE:}

The U.S Department of Energy's (DOE's) Connected Neighborhood project, supported by Building Technologies Office, includes two neighborhoods where ORNL researchers leverage DOE investment in micro-grids and responsive, flexible building loads research to improve grid reliability - a goal of DOE's Grid-interactive Efficient Buildings (GEB) Initiative.

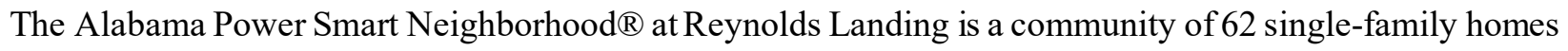
in suburban Birmingham, Alabama. It is the Southeast's first community custom-built to generate, store, and manage neighborhood electricity usage and efficiency. ORNL researchers are pioneering the application of smart, connected Internet-of-Things (IoT) devices to enable smart homes, promising to transform the nature of our power system from end-to-end. ORNL researchers began testing different methods of controlling smart building technologies shortly after the neighborhood became operational in fall 2017.

The second Smart Neighborhood, with Georgia Power, is Altus at the Quarter located in Atlanta, Georgia. The 46 townhomes in the neighborhood feature rooftop solar, home energy storage batteries and electrical vehicle chargers in addition to smart thermostats, hybrid heat pump water heaters and high efficiency HVAC systems. Construction of the Georgia Power neighborhood will finish in fall 2020, after which the 2-year research project will begin.

\section{WHAT'S BEING INVESTIGATED:}

The homes have been built according to high-efficiency construction techniques and have excellent Home Energy Rating System (HERS) scores of 45. In contrast homes built to current Alabama code (2015 International Energy Conservation Code) typically have a HERS of 70. The Reynolds Landing homes have HERS ratings that are approximately $35 \%$ more efficient than standard homes constructed to the current building code. Each home features state-of-the-art HVAC and water heating systems, including variable capacity heat pump HVACs, hybrid electric/heat pump water heaters, and internet-connected controls for both. 
ORNL researchers are testing different methods of controlling smart building technologies and distributed energy resources to pinpoint and optimize their individual and collective value in shaping the energy efficiency, energy management, and resiliency of buildings and electric grids. The project uses open-source optimization/control platforms together with commercial HVAC and water heater Application Program Interfaces (APIs) for deploying controls in residential neighborhoods.

ORNL researchers are also comparing different control approaches to test how advanced, energy-efficient building technologies like smart thermostats, heat pump water heaters, and advanced heat pump HVAC can be optimized at the home-level and connected as a neighborhood-scale load to a community microgrid. The neighborhood microgrid integrates $\sim 1 \mathrm{MW}$ natural gas-fired power generation, solar photovoltaics, and a battery storage system. ORNL is controlling the community microgrid with an open source microgrid controller known as CSEISMIC which ORNL developed with funding from DOE's Office of Electricity. CSEISMIC will help the utility achieve their desired load and cost profiles while ensuring the comfort of the homeowners.

This transactive control approach between neighborhood loads and microgrid maximizes the resources of the microgrid while reducing costs for both the homeowners and Alabama Power.

These tests partially seek to determine a more precise "range of tolerance with respect to occupant comfort" as researchers are deeply concerned about the customer acceptance and perception of new building technologies that enabling energy savings and a deeper integration into the utility. Technology must be a solution, not a burden to homeowners.

\section{RESULTS TO DATE:}

Transactive controls use software applications to monitor, control, and aggregate building resources.

Transactive controls:

- Enable responsive loads to be aggregated dynamically and 'transact' with the electric utility

- Enable seamless interoperability of data

- $\quad$ Provide value to the utility and to the customer

Measured data showed the homes in Reynolds Landing consumed 44\% less energy ( $\mathrm{kWh}$ ) -- a finding that has exceeded the estimation based on the HERS rating. The data also revealed the neighborhood peak winter heating electric demand $(\mathrm{kW})$ was $\mathbf{\sim 3 4 \%}$ less than that for a similar all-electric community. Reynolds Landing homes are highly energy efficient.

ORNL researchers compared data for standard operation versus grid-interactive operation in the Reynolds Landing homes and found that peak water heater and HVAC electric demand could be further reduced by more than $15 \%$ during peak price periods by controlling the systems to pre-heat, pre-cool, or otherwise manage to grid-related events (and different pricing structures). Reynolds Landing homes are Gridinteractive.

Alabama Power's Smart Neighborhood homes at Reynolds Landing are exemplary Grid-interactive Efficient Buildings. That's a significant result, especially in the national context, where residential and commercial buildings consume nearly $75 \%$ of the nation's electricity use and account for $40 \%$ of its total energy demand. Grid-interactive Efficient Buildings provide resource flexibility for the grid through behind-the-meter assets. 


\section{IMPACT TO HOMES, NEIGHBORHOODS AND BEYOND:}

One of the most important metrics to any utility leadership is customer satisfaction. Utilities are the trusted energy provider in a city - whether it is a local municipal utility, a rural electric utility or an investor owned utility. A utility has an imprint on a community - from the wire and infrastructure they support to the employees that service fellow neighbors and families. Consumers desire a better relationship with their energy providers - and Smart Neighborhoods have been shown as an effective bridge to develop and bolster those relationships.

Alabama Power's Smart Neighborhood is a testament to how homeowners trust and value a better relationship with their utilities. Whether it is from the added resilience, the added infrastructure to support the neighborhood, or the careful selection of smart home technologies, smart homes reinvest not only in the smart neighborhoods they form, but in the utilities that support the community. Sustainable community growth and healthy vibrant economies, communities and environments start with discussions between consumers and their utilities. Smart homes, neighborhoods, communities and cities are the future for sustainable, efficient and renewable-driven power - a growth founded on the relationship between customers and their utility.

The future grid aims to seamlessly provide cost-effective electricity, from generation to end-use, with the flexibility to accommodate clean energy sources and capacity requirements. However, the challenge of addressing variable resources is part of a larger grid modernization agenda which must address other profound changes in the nation's aging infrastructure. And, with IoT devices proliferating in today's homes, an opportunity exists to vastly expand the number of customers, types of end-uses engaged and the range of grid benefits derived by better utilizing buildings.

About ORNL: ORNL has 40-plus years of research and development leadership in building technologies, and has earned the respect of government agencies, industry, and universities in the U.S. and aboard. The Department of Energy's (DOE) Building Technologies Research and Integration Center (BTRIC) at Oak Ridge National Laboratory (ORNL) became operational in 1991 and was designated as a user facility in 1993 by DOE's Energy Efficiency and Renewable Energy (EERE) to answer the need for unique research capabilities for energy efficient buildings research in collaboration with industry, academia, associations, and other national labs. Today, BTRIC remains DOE's only designated national user facility dedicated to buildings energy efficiency, and in addition, offers a gateway to core capabilities at ORNL, including materials, neutrons, advanced manufacturing and high-performance computing. BTRIC addresses the need for unique state-of-the-art facilities, capabilities, and expertise to help discover, develop, evaluate, and accelerate innovative energy efficient building technology solutions. BTRIC staff have the proven ability to bridge the gap between basic science and early stage applied $\mathrm{R} \& \mathrm{D}$, and couple it to industry for later stage R\&D and implementation with economic impact and job creation from many industry partner products introduced into the market.

About ORNL's Buildings-to-Grid Activities: ORNL's work with Southern Company is a scientific exploration on how best to enable buildings-to-grid at an appreciable scale that can affect distribution utilities and potentially the bulk power system. ORNL's science based research enables Grid-interactive Efficient Buildings (GEB) through technical solutions such as battery equivalent modeling, portfolio 
control and management of responsive role, the appropriate role and use of model based optimizations and model predictive control, communication and connectivity architectures and their impacts to utility transactions, evaluation of consumer and grid benefits and impacts, enhanced efficiency gains with transactive control algorithms, and utility demand management strategies with improved response and impact without impacting comfort.

\begin{abstract}
About Southern Company: Southern Company is a leading energy company serving 9 million customers through its subsidiaries. The company provides clean, safe, reliable and affordable energy through electric operating companies in three states, natural gas distribution companies in four states, a competitive generation company serving wholesale customers across America, a leading distributed energy infrastructure company and a fiber optics network and telecommunication services. Southern Company operates as a regulated electric utility in Alabama, Mississippi and Georgia and maintains a unique relationship with its energy customers. For more than 50 years, Southern Company has maintained a robust $R \& D$ organization dedicated to discovering and developing new technologies to improve the operation at all facets of an energy utility. Southern Company's R\&D organization is responsible for managing multiple large projects, made possible through partnerships with the DOE, including next-generation nuclear and the National Carbon Capture Center. Southern Company is actively involved in buildings-to-grid research and is currently managing multiple large-scale field demonstrations and modeling activities, most notably the Alabama Power and Georgia Power Smart Neighborhoods.
\end{abstract}

For Additional Information Contact: Heather Buckberry, buckberryhl@ornl.gov, 865.576.2109 